\title{
Índices de chuva dirigida direcional e análise do nível de umedecimento em fachadas de edifício multipavimentos em Goiânia, GO
}

Directional driving rain index and analisys of the moisture level on facades of a multi -storey building in Goiânia, GO

\section{Carlos Mariano Melo Júnior Helena Carasek}

Resumo

$\Delta$ s fachadas dos edifícios estão sujeitas a condições de exposição que variam de acordo com as características climatológicas da região onde estão localizadas. A chuva dirigida, associação do vento à chuva, é uma das principais fontes externas de umidade e contribui com o processo de degradação dessas fachadas. $\mathrm{O}$ fenômeno é estudado em vários países e, devido à preocupação com seus efeitos, métodos vêm sendo desenvolvidos como forma de mensuração. Neste sentido, o presente trabalho visa obter os primeiros índices de chuva dirigida direcionais para a cidade de Goiânia-GO, bem como verificar a existência de relação desse índice com a umidade medida na superfície das fachadas de um edifício multipavimentos. Para tanto, os índices de chuva dirigida direcionais (ICDd) da média mensal e de janeiro foram calculados aplicando o método semi-empírico, considerando dados meteorológicos do período de 2002 a 2008. Posteriormente, foi realizada a medição experimental de umidade na superfície do revestimento das fachadas de um edifício com 17 pavimentos tipo. As medições foram realizadas sobre as fachadas revestidas com argamassa, no mês de janeiro, após um evento de precipitação pluviométrica. Como resultado, obteve-se que o ICDd da média de todos os meses dos anos analisados e o ICDd de janeiro indicam um comportamento diferenciado de chuva dirigida para cada orientação. As medições de umidade superficial nas fachadas do edifício apontaram a ocorrência de maior umedecimento para as fachadas voltadas à orientação $\mathrm{N}$, bem como no pavimento mais alto $\left(17^{\circ}\right)$ e nas regiões abaixo das janelas.

Carlos Mariano Melo Júnior Programa de Pós-Graduação em Geotecnia, Estruturas e Construção Civil, Escola de Engenharia Universidade Federal de Goiás Praça Universitária, s/n, Bloco A, Setor Universitário Goiânia - GO - Brasil CEP 74605-220

Tel.: (62) 8151-5669 E-mail:

carlosmmjunior@gmail.com

Helena Carasek Programa de Pós-Graduação em Geotecnia, Estruturas e Construção Civil, Escola de Engenharia

Universidade Federal de Goiás Tel.: (62) 8111-4764 E-mail: hcarasek@gmail.com

Recebido em 15/04/11 Aceito em 18/08/11
Palavras-chave: Durabilidade. Chuva dirigida. Umidade. Fachada.

\section{Abstract}

Building facades are subject to exposure conditions that vary according to the climate characteristics of the region where they are located. Driving rain, wind associated with rain, is a major source of moisture and contributes with the degradation process of those facades. The phenomenon is being studied in several countries and, due to concerns about its effects, different methods for measuring it have been devised. This study aims to obtain a directional driving rain index of the city of Goiania, as well as check whether these indices bear a relationship with the moisture measured on the façade surfaces of a multi-storey building. In order to do that, the directional driving rain index of the monthly average and that of January were calculated applying the semi-empirical method, considering meteorological data of the period 2002 to 2008. Subsequently, experimental measurements of moisture on the surface of the facade rendering of a 17-storey building were carried out. The measurements were made on the facades rendered with mortar, after a rainfall in the month of January. The directional driving rain index of the monthly average of the years analyzed and of January indicated a differential behaviour of driving rain for each direction. The superficial moisture measurements of the building facades indicated the occurrence of higher moisture on north-facing facades, as well as on the higher floor (17th) and in the areas below windows.

Keywords: Durability. Driving rain. Moisture. Facades. 


\section{Introdução}

A durabilidade dos sistemas que compõem o edifício está voltada à agressividade do meio ambiente onde está inserido, assim como às propriedades dos elementos e componentes. Entre os sistemas que compõem o edifício, as fachadas estão sujeitas às condições de exposição, que variam de acordo com as características climatológicas da região onde estão localizadas. Os elementos climáticos (precipitação pluviométrica, precipitação de neve e de granizo, vento, radiação solar, umidade relativa e temperatura) contribuem com o processo de degradação e afetam diretamente a durabilidade das fachadas. A precipitação pluviométrica é uma das principais fontes de umidade dos edifícios, sendo, portanto, uma vertente de preocupação, pois não é possível sua eliminação, uma vez que é regida pelas leis da natureza. Nesse sentido, Choi (1999) afirma que a degradação causada pela água da chuva vem sendo há muito tempo reconhecida como o principal problema na manutenção de edificações. Perez (1988) aponta as manifestações patológicas pela presença de umidade como uma das mais difíceis de ser combatidas devido à complexidade e carência de estudos do fenômeno. De acordo com Souza, Almeida e Verçosa (2005), os efeitos pelo aparecimento desse problema grave, de difícil solução e também dispendioso são a perda da funcionalidade da edificação, danos a equipamentos e bens no interior do edifício, desconforto aos usuários com riscos à saúde e prejuízos financeiros, seja em decorrência dos percalços citados, como pelos custos com reparação das falhas apresentadas pelo edifício.

A presença de umidade em abundância contribui com uma série de problemas, tais como a corrosão eletroquímica de metais, a proliferação de microrganismos, a descoloração dos revestimentos de fachadas, a formação de manchas e eflorescências, além da variação dimensional de componentes, materiais e elementos construtivos, como o concreto, o revestimento de argamassa, blocos de alvenaria, gesso, etc.

A chuva dirigida é um fenômeno climático que tem sua origem na associação da chuva e do vento, sendo considerada por Straube e Burnett (2000) como a maior fonte de umidade que as fachadas de um edifício podem receber do meio externo; por essa razão, ela afeta diretamente o desempenho da edificação. Ainda para os autores citados, a análise do comportamento higrotérmico e da durabilidade de fachadas requer a quantificação da carga de chuva dirigida.

Gaspar e Brito (2005), em estudos realizados nas cidades de Lisboa, Alcochete e Tavira, em Portugal, identificaram que $25 \%$ dos problemas de degradação em fachadas de edifícios revestidas com argamassa de base cimentícia e com acabamento decorativo em pintura são decorrentes da chuva dirigida e do escoamento superficial de água na fachada.

A complexidade do fenômeno e o surgimento de manifestações patológicas têm instigado a comunidade científica e, por essa razão, pesquisadores de vários países têm buscado estabelecer mecanismos para mensurar a chuva dirigida, empregando equações semiempíricas, medições experimentais ou mesmo simulações numéricas do fenômeno. Apesar da importância, no Brasil existem poucos estudos sobre a chuva dirigida, e talvez uma das explicações para isso seja a dificuldade em se obterem dados climáticos da parte das estações meteorológicas.

\section{Revisão da literatura}

A associação de vento e chuva ("precipitação pluviométrica" ou simplesmente "precipitação", termo mais usado) cria o vetor de intensidade de chuva oblíqua. A partir da compreensão da relação entre chuva e as fachadas de edificações, o termo "intensidade de chuva dirigida" restringe-se à componente de vetor de intensidade de chuva que causa fluxo de água sobre um plano vertical, definição esta adotada pelo International Council for Building Research and Innovation (CIB) (BLOCKEN; CARMELIET, 2004).

Segundo Thomaz (1990), sem a incidência de vento, as gotas de chuva cairiam verticalmente e as fachadas pouco seriam umedecidas. Porém, com a presença do vento, as fachadas passam a se expor em diferentes níveis de umidade, diretamente influenciados pela direção e intensidade do vento (Figura 1).

Devido à incidência de vento, as fachadas da edificação ilustrada anteriormente são atingidas de maneira diferenciada, pois as faces A, B e C estão expostas à água da chuva, enquanto a face $\mathrm{D}$ não está. As faces A e B ainda seriam mais agredidas pelo acúmulo de água em decorrência do escoamento da água pela face $\mathrm{C}$. 


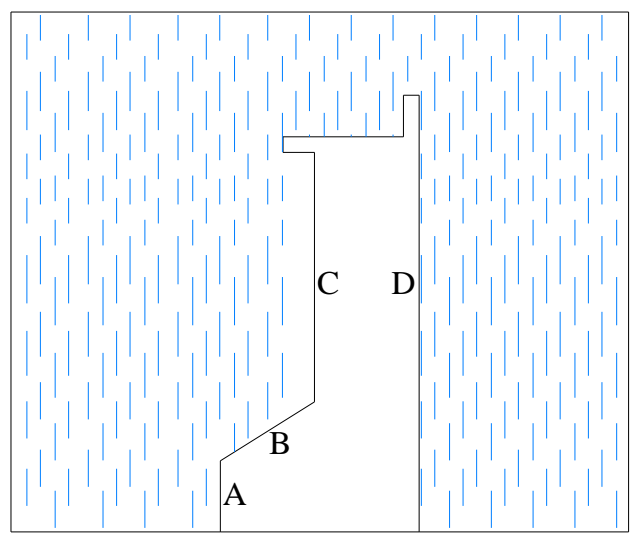

(a)

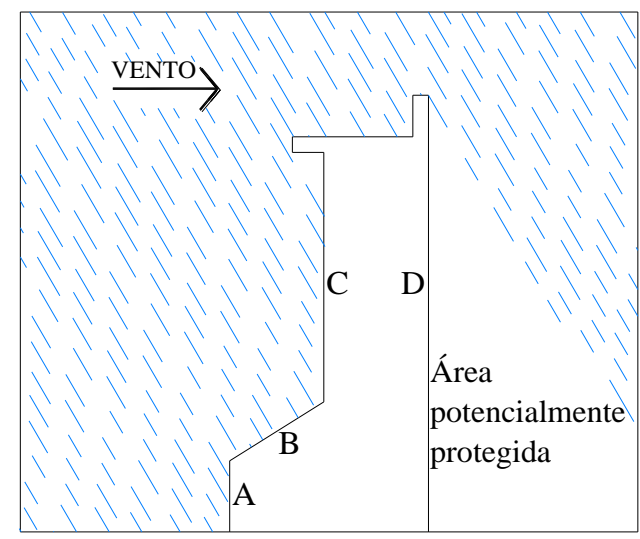

(b)

Figura 1 - Influência do vento na direção da chuva e na exposição das fachadas: (a) situação sem vento e (b) situação com vento

Fonte: Thomaz (1990).

As medições dos padrões meteorológicos realizadas nas estações abrangem, entre outras, velocidade e direção de vento, além de pluviometria. No entanto, o índice de chuva dirigida, por não ser obtido por estações climatológicas padronizadas, estimulou o desenvolvimento de métodos baseados nas medições de elementos climáticos. Existem três métodos para a mensuração da chuva dirigida, que são os experimentais, os numéricos e os semiempíricos.

Os métodos experimentais consistem em medições de chuva dirigida por meio de coletores específicos. Assim como os aparelhos que medem a intensidade pluviométrica, os medidores WDR (Wind Driven Rain gauges) coletam, através de aberturas verticais, o montante de chuva dirigida, diferenciando-se dos medidores pluviométricos, que são horizontais. Aqueles aparelhos não são produzidos industrialmente e tampouco normalizados, o que os leva a diferentes formatos e tamanhos. Resumem-se a bandejas que são dispostas no plano vertical, que captam a chuva dirigida, levando-a para reservatórios de medição (BLOCKEN; CARMELIET, 2004).

Entre os métodos numéricos, o CFD (Computational Fluid Dynamics) é um método que permite o estudo das trajetórias de gotas de chuva com base em cálculos de padrões de fluido em torno de edificações em 2D (duas dimensões). Blocken e Carmeliet (2004) afirmam que Choi (1999) criou um divisor de tempos para os métodos numéricos de pesquisas de chuva dirigida ao desenvolver o método numérico, no qual a trajetória das gotas de chuva é calculada baseada em um estado fixo padrão de fluência de vento em 3D (três dimensões).
Os métodos semiempíricos baseiam-se em relações entre os dados de vento e precipitação pluviométrica e, segundo Blocken e Carmeliet (2004), durante os anos 60, o CIB estabeleceu que o índice de chuva dirigida (ICD) é o produto entre a velocidade média do vento e a quantidade total de precipitação. A Equação 1 apresenta a expressão para o cálculo do ICD.

$I C D=V \cdot \frac{P}{1000}$

Eq. 1

Onde:

$I C D=$ índice de chuva dirigida $\left(\mathrm{m}^{2} / \mathrm{s}\right)$;

$V=$ velocidade média de vento $(\mathrm{m} / \mathrm{s})$; e

$P=$ total de precipitação $(\mathrm{mm})$.

A partir da média anual de vento e da precipitação total, é possível fazer o cálculo do ICD anual para qualquer região. Esse método foi baseado em uma das relações propostas primeiramente por Hoppestad, em 1955, na Noruega, para a criação do primeiro mapa de chuva dirigida (BLOCKEN; CARMELIET, 2004).

Como parâmetros para enquadrar as edificações e suas respectivas regiões em níveis de agressividade, Lacy (1977 ${ }^{1}$ apud CHAND; BHARGAVA, 2002) adota três faixas de exposição à chuva dirigida, de acordo com o ICD anual, como se apresenta na Tabela 1.

Porém, Chand e Bhargava (2002) propuseram uma quarta faixa, considerando as condições severas de ambiência para valores de ICD maiores do que 11 $\mathrm{m}^{2} / \mathrm{s}$, como apresentado na Tabela 2 .

${ }^{1}$ LACY, R. E. Climate and Building in Britain: building research establishment. London: Her Majesty's Stationery Office, 1977. $185 \mathrm{p}$. 
Tabela 1 - Faixas de exposição à chuva dirigida propostas por Lacy (1977) ${ }^{2}$

\begin{tabular}{cc}
\hline Faixa & Grau de exposição \\
\hline $\mathrm{ICD} \leq 3 \mathrm{~m}^{2} / \mathrm{s}$ & Protegida ou branda \\
$3 \mathrm{~m}^{2} / \mathrm{s}<\mathrm{ICD} \leq 7 \mathrm{~m}^{2} / \mathrm{s}$ & Moderada \\
$\mathrm{ICD}>7 \mathrm{~m}^{2} / \mathrm{s}$ & Severa \\
\hline
\end{tabular}

Tabela 2 - Faixas de exposição à chuva dirigida propostas por Chand e Bhargava (2002)

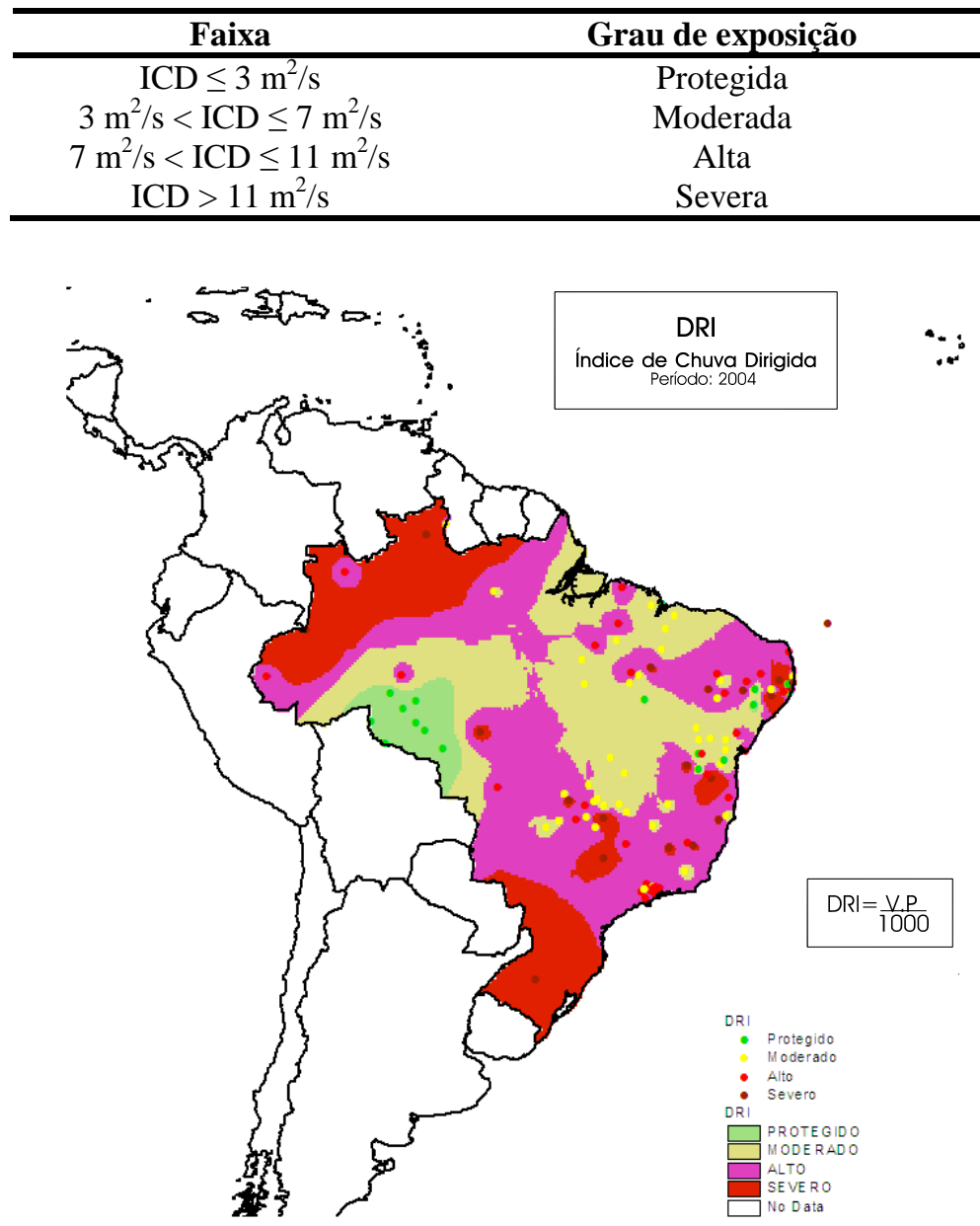

Figura 2 - Mapa brasileiro de chuva dirigida com base nos dados de 2004

Fonte: Lima e Morelli (2005).

Segundo Marsh (1977), cabe ainda salientar que, para as distâncias menores que $8 \mathrm{~km}$ do mar, nas áreas com ICD menores que $3 \mathrm{~m}^{2} / \mathrm{s}$, a exposição deve ser considerada moderada, e entre $5 \mathrm{~m}^{2} / \mathrm{s}$ e $7 \mathrm{~m}^{2} / \mathrm{s}$, a exposição deve ser considerada severa.

O primeiro mapa de chuva dirigida no Brasil foi desenvolvido por Lima e Morelli (2005), adotando-se as quatro faixas de exposição propostas por Chand e Bhargava (2002). Observase que esse mapa, ilustrado na Figura 2, não apresenta os índices de chuva dirigida direcionais (ICDd), trazendo apenas informações do grau de exposição. O mapa foi elaborado com os dados disponíveis na página do site do Centro de Previsão de Tempo e Estudos Climáticos (CPTEC) de 2004.

Apesar de o mapa brasileiro de chuva dirigida conter informações sobre o nível de exposição em todo o território, possibilitando prever os riscos quanto à agressividade do meio ao qual a edificação se encontra, ele não permite conhecer quais fachadas estão mais suscetíveis às manifestações patológicas por não conter o índice de chuva dirigida direcional (ICDd).

${ }^{2}$ LACY, R. E. Climate and Building in Britain: building research establishment. London: Her Majesty's Stationery Office, 1977. $185 \mathrm{p}$.

26 Melo Júnior, C. M.; Carasek, H. 
A partir da Equação 1, pode-se calcular também o ICDd, apresentando-se os resultados em forma de gráficos do tipo "radar" ou "roseta", com a finalidade de visualizar quais fachadas da edificação estão mais expostas à chuva dirigida em determinada localidade. Giongo (2007) apresenta em seu estudo os primeiros índices de chuva dirigida direcionais no Brasil, especificamente para a cidade de Florianópolis, não existindo ainda esses índices calculados para as demais cidades e regiões brasileiras.

\section{Objetivo}

O objetivo do presente trabalho é obter os primeiros índices de chuva dirigida direcionais pelo método semiempírico para a cidade de Goiânia, GO, bem como verificar a existência de relação desse índice com a umidade medida na superfície das fachadas de um edifício multipavimentos.

\section{Método de pesquisa}

O presente trabalho foi desenvolvido em duas etapas. A primeira etapa visou calcular, pelo método semiempírico, os índices de chuva dirigida direcionais para a cidade de Goiânia, GO. A segunda etapa visou medir experimentalmente a umidade superficial de alguns pontos das fachadas de um edifício multipavimentos.

Geograficamente, a cidade de Goiânia está localizada na latitude $16^{\circ} 41^{\prime}$ sul, na longitude $49^{\circ} 17^{\prime}$ oeste, e possui clima predominante tropical úmido. A região onde se encontra apresenta duas características significativas: a continentalidade, pela distância com o oceano Atlântico, e a grande regularidade do processo cíclico dos deslocamentos de massas de ar, que, associada a outros aspectos, cria um regime pluviométrico bem definido. Assim, essa região possui uma estação chuvosa (nos meses de novembro, dezembro, janeiro, fevereiro e março - cerca de 5 meses com precipitação acima dos $200 \mathrm{~mm}$ mensais), uma estação seca (nos meses de junho, julho e agosto), além de uma estação intermediária (meses de abril e maio, e, posteriormente, entre setembro e outubro). A umidade relativa acompanha a variação do ciclo da chuva durante o ano, mas, enquanto o índice pluviométrico tem uma variação abrupta entre os meses do ano, a umidade relativa apresenta uma variação discreta. Salienta-se também que, de acordo com Fernandes (2006), para a estação chuvosa, a primeira predominância de direção de vento é norte, mudando, no entanto para leste durante o período seco.
$\mathrm{Na}$ sequência estão descritas as atividades realizadas nas duas etapas da pesquisa.

\section{Cálculo de Índices de Chuva Dirigida Direcionais (ICDd)}

Para o cálculo dos índices de chuva dirigida direcionais (ICDd) adotou-se o método semiempírico, discutido anteriormente. A adoção desse método baseou-se nos resultados significativos que vários autores internacionais obtiveram, tais como Lacy $\left(1977^{3}\right.$ apud CHAND; BHARGAVA, 2002) e Chand e Bhargava (2002).

Para tanto, foram obtidos dados meteorológicos horários da estação automática do $10^{\circ}$ Décimo Distrito Meteorológico (Disme), do Instituto Nacional de Meteorologia (Inmet), no período de 2002 a 2008. Essa estação está posicionada na latitude $16^{\circ} 38^{\prime} 32^{\prime \prime}$ sul e longitude $49^{\circ} 13$ ' $12^{\prime \prime}$ oeste, e localizada no setor Jaó, Goiânia, GO. Isso gerou um total de 183.960 dados, referentes às medições de hora em hora de precipitação pluviométrica, bem como de velocidade e de direção do vento durante todo o período de 2002 a 2008 . $^{4}$

Nessa estação automática, os dados de precipitação são registrados em milímetros, velocidade de vento, em metros por segundo, e direção de vento, em graus. Assim, não foi necessária a transformação de unidades para velocidade de vento e precipitação. Para o cálculo do ICDd, no entanto, os dados de direção de vento - registrados em graus - foram transformados em oito direções, cada uma abrangendo $45^{\circ}$, como se apresenta na Figura 3, a seguir, que são: norte $(\mathrm{N})$, nordeste $(\mathrm{NE})$, leste (E), sudeste (SE), sul (S), sudoeste $(\mathrm{SO})$, oeste $(\mathrm{O})$ e noroeste $(\mathrm{NO})$.

A transformação também para os pontos colaterais (NE, SE NO e SO) possibilita um maior detalhamento da chuva dirigida para as localidades, uma vez que se passa a ter mais quatro pontos de estudos em relação aos pontos cardeais (N, E, S e O). Depois da transformação das direções de vento para as oito orientações, foi realizado o agrupamento das observações (velocidade de vento e precipitação) para as respectivas orientações, excluindo-se as observações com ventos de velocidade inferior a 1 nó $(0,5144 \mathrm{~m} / \mathrm{s})$, uma vez que estes são considerados ventos calmos.

\footnotetext{
${ }^{3}$ LACY, R. E. Climate and Building in Britain: building research establishment. London: Her Majesty's Stationery Office, 1977. $185 \mathrm{p}$.

4 A estação automática do $10^{\circ}$ Disme teve suas primeiras medições no dia 26 de maio de 2001 e por esse motivo somente foram calculados os índices de chuva dirigida direcional a partir de 2002. Por não se possuírem todos os dados de 2001, esse ano não foi considerado.
} 


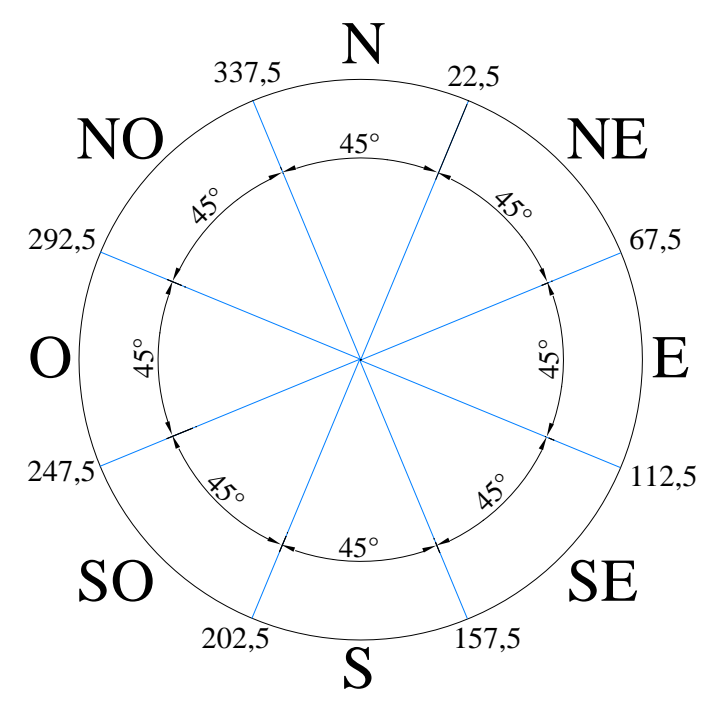

Figura 3 - Transformação das direções de vento medidas em graus para as direções N, NE, E, SE, S, SO, $\mathrm{O}$ e NO

Foram calculados dois índices: a média do ICDd mensal no período de 2002 a 2008 (todos os meses) e o ICDd específico do mês de janeiro no mesmo período (2002 a 2008), mês chuvoso da cidade de Goiânia.

Para o cálculo da média de ICDd mensal foi empregada a Equação 1, apresentada anteriormente, e foram adotadas as seguintes etapas:

(a) somatório dos totais de precipitação $(\mathrm{P})$ para cada direção e mês, no período de 2002 a 2008;

(b) média de velocidade de vento com chuva (V) para cada direção e mês no período de 2002 a 2008; e

(c) c) cálculo do ICD $\left(\mathrm{m}^{2} / \mathrm{s}\right)$ utilizando os dados dos itens (a) e (b) para cada direção.

Para o cálculo do ICDd de janeiro foi empregada também a Equação 1, apresentada anteriormente, e foram adotadas as seguintes etapas:

(a) somatório dos totais de precipitação $(\mathrm{P})$ para cada direção no mês de janeiro, no período de 2002 a 2008;

(b) média de velocidade de vento com chuva (V) para cada direção no mês de janeiro no período de 2002 a 2008; e

(c) c) cálculo do ICD ( $\left.\mathrm{m}^{2} / \mathrm{s}\right)$ utilizando os dados dos itens (a) e (b) para cada direção.

\section{Medição de umidade superficial em fachadas}

Nesta etapa foram realizadas as medições de umidade em vários pontos da superfície do revestimento de argamassa das quatro fachadas de um edifício multipavimentos, conforme descrição a seguir.

\section{Características da edificação}

As medições foram realizadas sobre as fachadas revestidas de um edifício em fase de construção, com 17 pavimentos-tipo (Figura 4). Esse edifício está localizado no setor Negrão de Lima, na cidade de Goiânia, latitude 16 39'18" e longitude 49 14'31', portanto, próximo da estação meteorológica do $10^{\circ}$ Disme. As fachadas possuíam revestimento de argamassa mista (cimento e cal) ainda sem o acabamento decorativo, no caso a pintura texturizada acrílica.

\section{Método de medição}

Para a medição de umidade foi escolhido um dia qualquer do período chuvoso característico da região de Goiânia, no mês de janeiro, onde nas 24 horas que antecederam as medições constatou-se, à 1 h00, vento com velocidade de $1,6 \mathrm{~m} / \mathrm{s}$ e com predominância a $338^{\circ}$, bem como precipitação pluviométrica de 7,4 mm (Tabela 3). Assim, quatro horas após o término da chuva, foram feitas as medições, entre $15 \mathrm{~h} 00$ e $16 \mathrm{~h} 00$. 


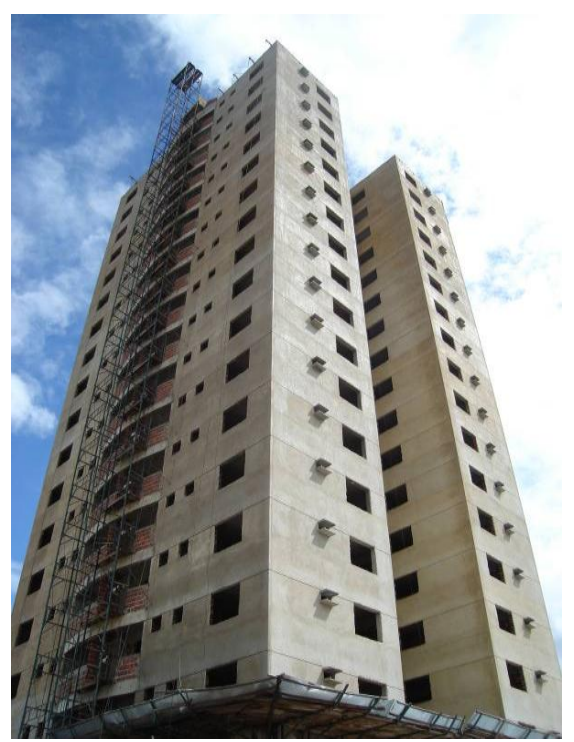

Figura 4 - Edificação onde foram realizadas as medições de umidade

Tabela 3 - Medições da estação automática do INMET

\begin{tabular}{ccccc}
\hline & & \multicolumn{2}{c}{ Vento $(\mathrm{m} / \mathrm{s})$} & \\
\cline { 3 - 4 } Data & Hora (UCT) & $\begin{array}{c}\text { Velocidade } \\
(\mathrm{m} / \mathrm{s})\end{array}$ & $\begin{array}{c}\text { Direção } \\
\text { em graus }\end{array}$ & Chuva $(\mathrm{mm})$ \\
\hline $7 / 1 / 2010$ & $15: 00$ & 1,6 & $338^{\circ}$ & 0,0 \\
$7 / 1 / 2010$ & $16: 00$ & 1,2 & $338^{\circ}$ & 0,0 \\
$7 / 1 / 2010$ & $17: 00$ & 1,6 & $338^{\circ}$ & 0,0 \\
$7 / 1 / 2010$ & $18: 00$ & 0,5 & $338^{\circ}$ & 0,0 \\
$7 / 1 / 2010$ & $19: 00$ & 0,8 & $338^{\circ}$ & 0,0 \\
$7 / 1 / 2010$ & $20: 00$ & 1,8 & $338^{\circ}$ & 0,0 \\
$7 / 1 / 2010$ & $21: 00$ & 1,5 & $338^{\circ}$ & 0,0 \\
$7 / 1 / 2010$ & $22: 00$ & 2,9 & $338^{\circ}$ & 0,0 \\
$7 / 1 / 2010$ & $23: 00$ & 0,8 & $338^{\circ}$ & 0,0 \\
$8 / 1 / 2010$ & $0: 00$ & 2,1 & $338^{\circ}$ & 2,0 \\
$8 / 1 / 2010$ & $1: 00$ & 1,6 & 338 & 7,4 \\
$8 / 1 / 2010$ & $2: 00$ & 1,3 & $338^{\circ}$ & 0,2 \\
$8 / 1 / 2010$ & $3: 00$ & 1,2 & $338^{\circ}$ & 0,0 \\
$8 / 1 / 2010$ & $4: 00$ & 1,8 & $338^{\circ}$ & 0,2 \\
$8 / 1 / 2010$ & $5: 00$ & 0,8 & $338^{\circ}$ & 1,0 \\
$8 / 1 / 2010$ & $6: 00$ & 0,2 & $338^{\circ}$ & 0,8 \\
$8 / 1 / 2010$ & $7: 00$ & 0,0 & $338^{\circ}$ & 0,8 \\
$8 / 1 / 2010$ & $8: 00$ & 0,2 & $338^{\circ}$ & 0,4 \\
$8 / 1 / 2010$ & $9: 00$ & 0,4 & $338^{\circ}$ & 0,8 \\
$8 / 1 / 2010$ & $10: 00$ & 0,0 & $338^{\circ}$ & 0,4 \\
$8 / 1 / 2010$ & $11: 00$ & 1,1 & $338^{\circ}$ & 0,2 \\
$8 / 1 / 2010$ & $12: 00$ & 0,9 & $338^{\circ}$ & 0,0 \\
$8 / 1 / 2010$ & $13: 00$ & 1,5 & $338^{\circ}$ & 0,0 \\
$8 / 1 / 2010$ & $14: 00$ & 1,3 & $338^{\circ}$ & 0,0 \\
$8 / 1 / 2010$ & $15: 00$ & 2,2 & $338^{\circ}$ & 0,0 \\
\hline
\end{tabular}




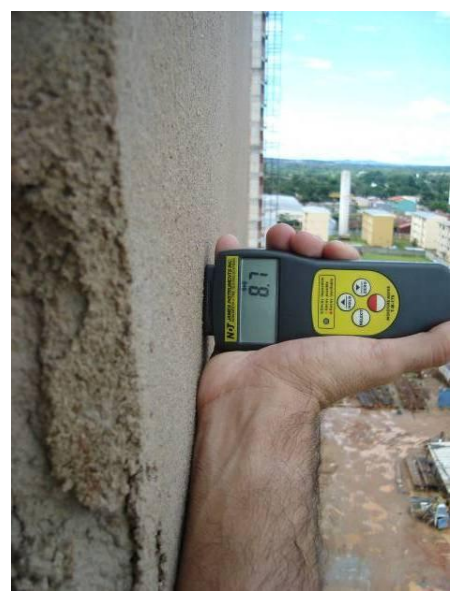

Figura 5 - Medição realizada na fachada norte do $9^{\circ}$ andar, ao lado da janela, próximo à fachada oeste

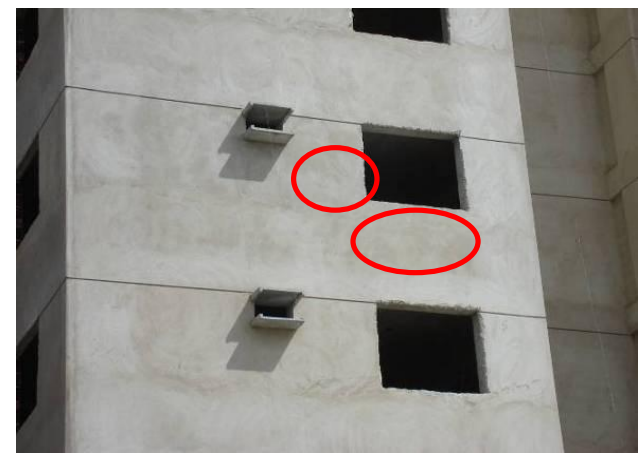

Figura 6 - Regiões da fachada (embaixo e ao lado da abertura da janela) onde foram realizadas as medições de umidade

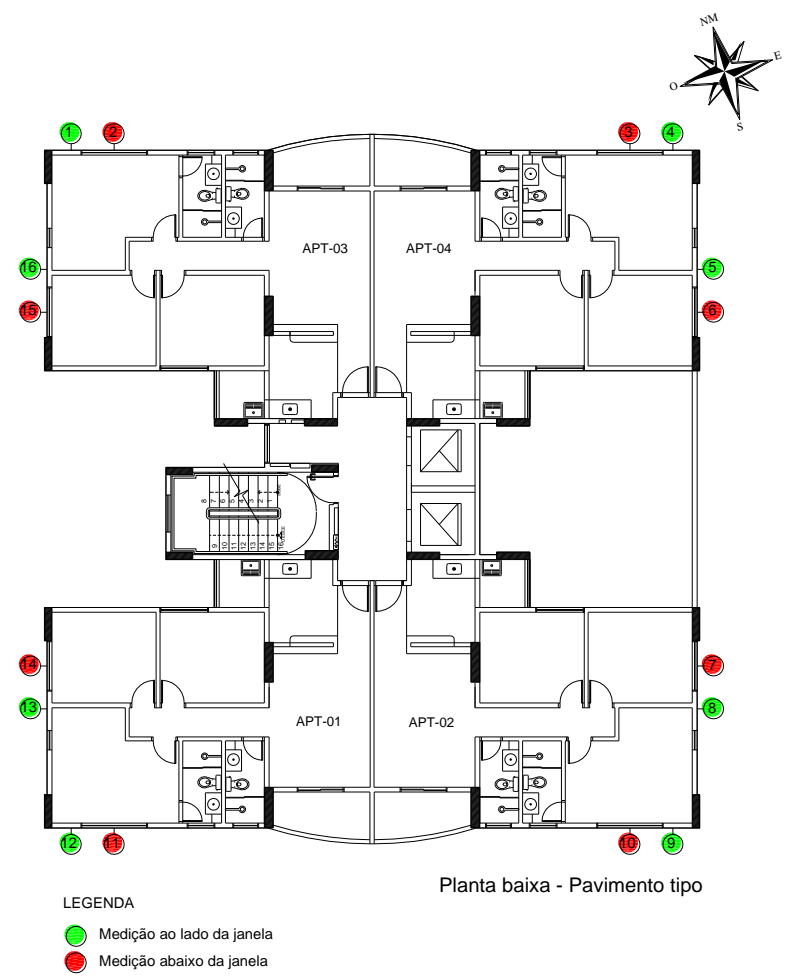

Figura 7 - Pavimento-tipo e local do edifício onde foram realizadas as medições de umidade 
Para as medidas de umidade foi empregado um medidor de umidade superficial digital, Moisture Meter M-T-170 (James T-M), para materiais sólidos (tijolos, concreto, argamassa, gesso e madeira), com faixa de medida $0-80 \%$ de conteúdo de água e resolução de 0,1\%, ilustrado na Figura 5.

Ao todo, foram realizadas 48 medições, em três pavimentos-tipo: $2^{\circ}, 9^{\circ}$ e $17^{\circ}$ andares. Em cada pavimento, foram realizadas 16 medições, quatro para cada orientação (N, S, E e O). Para cada fachada dos pavimentos analisados foram feitas medições abaixo e ao lado da janela, como indicado na Figura 6, sendo duas para cada extremo da fachada, isto é, mais à esquerda e mais à direita da fachada, como indicado na Figura 7.

\section{Resultados e discussão}

Os resultados de índice de chuva dirigida direcional calculados foram representados na forma de gráficos do tipo radar, com a finalidade de visualizar facilmente as direções predominantes de chuva dirigida. Na Figura 8 ilustra-se a resultante da média de ICDd mensal no período de 2002 a 2008.

Observa-se na Figura 8 que os maiores valores de ICDd médio correspondem aos quadrantes NO e
SE $\left(0,23 \mathrm{~m}^{2} / \mathrm{s}\right)$, e o menor valor, ao quadrante $\mathrm{S}$ $\left(0,09 \mathrm{~m}^{2} / \mathrm{s}\right)$

Na Figura 9 apresenta-se a resultante do ICDd específico para o mês de janeiro, no período estudado (2002 a 2008), onde se observam os maiores valores nos quadrantes $\mathrm{N}$ e $\mathrm{NO}$ $\left(0,50 \mathrm{~m}^{2} / \mathrm{s}\right)$, e o menor valor, no quadrante $\mathrm{S}$ $\left(0,06 \mathrm{~m}^{2} / \mathrm{s}\right)$.

O ICDd da média mensal no período de 2002 a 2008 apresentou resultados menores em relação ao ICDd do mês chuvoso de janeiro, que pode ser explicado pela diminuição da chuva dos períodos secos. Apesar disso, nesses períodos, alguns eventos de chuva foram registrados e, considerando a intensidade de vento associada às direções SE e S, esses quadrantes apresentam valores significativos de índices de chuva dirigida direcionais.

Porém, no mês de janeiro, muito chuvoso, os índices de chuva dirigida direcionais apresentaram valores muito altos em relação à média mensal de ICDd, principalmente para os quadrantes $\mathrm{N}$ e $\mathrm{NO}$ $\left(0,50 \mathrm{~m}^{2} / \mathrm{s}\right)$. Giongo (2007) apresenta os índices de chuva dirigida direcionais sazonais para Florianópolis no período de 1961-1970, onde o quadrante com maior índice foi o $\mathrm{S}$, com valores aproximados de $0,43 \mathrm{~m}^{2} / \mathrm{s}$.

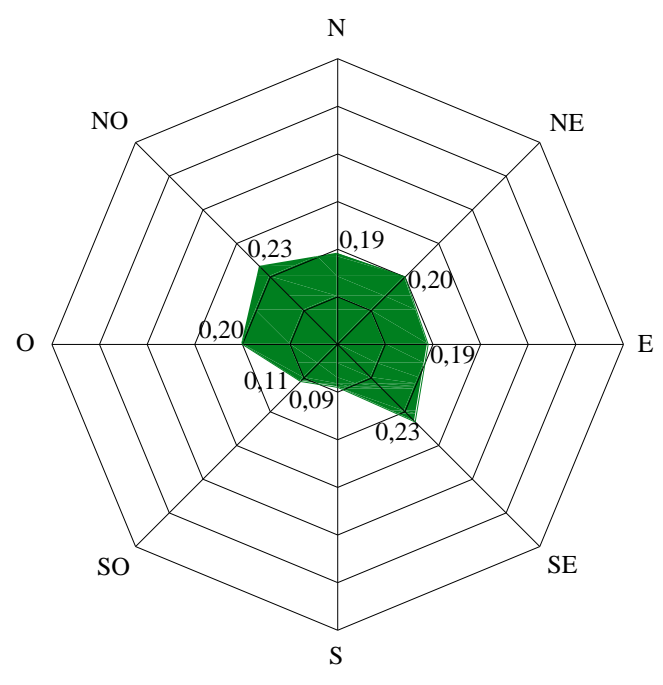

MÉDIA MENSAL - 2002 a 2008

Figura 8 - Média dos índices de chuva dirigida direcionais de todos os meses $\left(\mathrm{m}^{2} / \mathrm{s}\right)$, para o período de 2002 a 2008, para Goiânia 


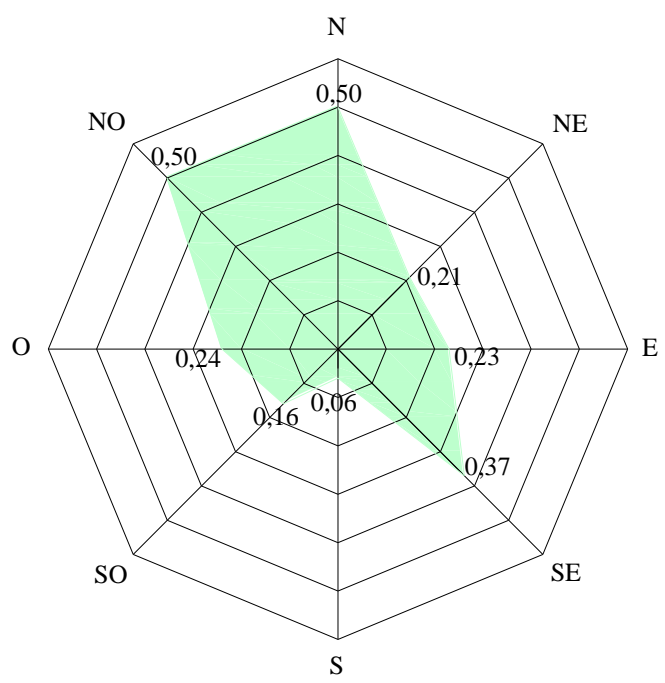

JAN 2002 a 2008

Figura 9 - Índice de chuva dirigida direcional $\left(\mathrm{m}^{2} / \mathrm{s}\right)$ para o mês de janeiro nos anos de 2002 a 2008 para Goiânia

Tabela 4 - Medições de umidade superficial realizadas nas fachadas do edifício

\begin{tabular}{|c|c|c|c|c|c|c|c|}
\hline \multirow[b]{3}{*}{$\begin{array}{l}\text { Orientação } \\
\text { da fachada }\end{array}$} & \multirow[b]{3}{*}{$\begin{array}{l}\text { Proximidade } \\
\text { da fachada }\end{array}$} & \multicolumn{6}{|c|}{ Pavimentos } \\
\hline & & \multicolumn{2}{|c|}{$2^{\circ}$ andar } & \multicolumn{2}{|c|}{$9^{\circ}$ andar } & \multicolumn{2}{|c|}{$17^{\circ}$ andar } \\
\hline & & $\begin{array}{c}\text { Embaixo } \\
\text { da } \\
\text { janela } \\
(\%)\end{array}$ & $\begin{array}{c}\text { Ao lado } \\
\text { da } \\
\text { janela } \\
(\%)\end{array}$ & $\begin{array}{c}\text { Embaixo } \\
\text { da } \\
\text { janela } \\
(\%)\end{array}$ & $\begin{array}{c}\text { Ao lado } \\
\text { da } \\
\text { janela } \\
(\%)\end{array}$ & $\begin{array}{c}\text { Embaixo } \\
\text { da } \\
\text { janela } \\
(\%)\end{array}$ & $\begin{array}{c}\text { Ao lado } \\
\text { da } \\
\text { janela } \\
(\%)\end{array}$ \\
\hline \multirow{2}{*}{$\mathbf{N}$} & Leste & 9,1 & 8,4 & 12,6 & 11,3 & 11,4 & 8,8 \\
\hline & Oeste & 16,0 & 14,7 & 10,2 & 8,7 & 12,9 & 9,5 \\
\hline \multirow{2}{*}{$\mathbf{E}$} & Norte & 6,6 & 4,5 & 3,7 & 3,6 & 3,3 & 3,9 \\
\hline & Sul & 3,5 & 3,8 & 4,3 & 3,1 & 6,0 & 3,9 \\
\hline \multirow{2}{*}{$\mathbf{S}$} & Leste & 4,8 & 3,4 & 4,1 & 3,5 & 3,9 & 3,6 \\
\hline & Oeste & 4,9 & 3,7 & 3,1 & 3,0 & 3,6 & 3,4 \\
\hline \multirow{2}{*}{ O } & Norte & 4,9 & 3,6 & 4,1 & 3,3 & 10,1 & 5,2 \\
\hline & Sul & 4,0 & 4,0 & 5,3 & 4,3 & 8,8 & 8,3 \\
\hline
\end{tabular}

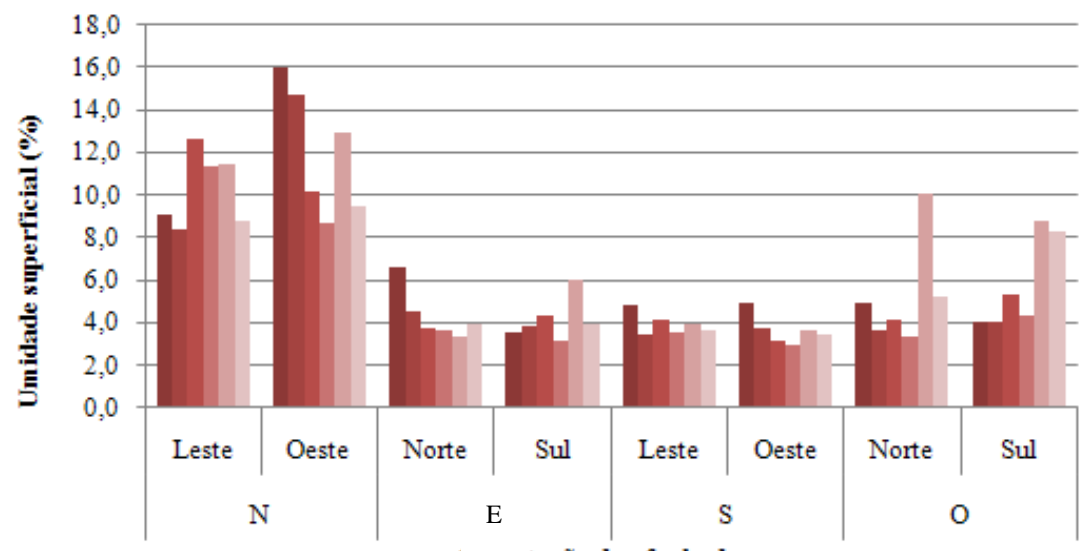

Urientação das fachadas

- Pavimento: $2^{\circ}$ andar - embaixo da janela
n Pavimento: $9^{\circ}$ andar - embaixo da janela
Pavimento: $2^{\circ}$ andar - ao lado da janela

- Pavimento: $17^{\circ}$ andar - embaixo da janela Pavimento: $17^{\circ}$ andar - ao lado da janela

Figura 10 - Umidade superficial em função da orientação da fachada, medida nos diversos pavimentos 
A Tabela 4 e a Figura 10 apresentam os resultados das medições de umidade.

A umidade superficial medida variou de $3 \%$ a $16 \%$, mostrando regiões onde o revestimento está praticamente saturado, uma vez que absorção total de argamassas mistas varia geralmente entre $15 \%$ e $20 \%$. A fachada voltada à orientação $\mathrm{N}$ apresentase com os maiores valores de umidade superficial, sendo, para a medição realizada mais a oeste da mesma fachada, os valores maiores que os valores a leste da edificação. As fachadas com orientações $E$ e $S$ possuem, de maneira geral, valores próximos, e a fachada voltada a $\mathrm{O}$ apresenta valores um pouco maiores que os das fachadas $\mathrm{E} e$ $\mathrm{S}$, principalmente no $17^{\circ}$ pavimento. Isso é explicado pelo fato de que a direção do vento predominou a $338^{\circ}$ na véspera da medição.

Em relação à localização onde foram realizadas as medições, verificam-se maiores valores para as medições embaixo das janelas, em todas as fachadas, em comparação às medições realizadas ao lado das janelas, conforme pode ser visto na Tabela 5 e na Figura 11.
Essa constatação, tendência de maior umidade abaixo das janelas, pode indicar um local potencial de manchamento da fachada no futuro, com manchas do tipo "bigode". Salienta-se, no entanto, que a edificação no instante da medição da umidade superficial não tinha ainda esquadrias e acabamento dos peitoris, o que pode ter também influenciado nessa maior umidade, que, nesse caso, seria reduzida quando do término da construção, com os acabamentos executados.

Na Tabela 6 e na Figura 12 são demonstrados os valores de medição de umidade por andar e por orientação da fachada. $\mathrm{O} 17^{\circ}$ andar apresenta o maior valor médio, estando o $2^{\circ}$ andar com o segundo maior valor médio, e o $9^{\circ}$ andar com o menor valor médio. Um valor de umidade mais elevado no último pavimento era esperado, como demonstrado em algumas pesquisas que se utilizaram de observações de edificações em escala real, modelos reduzidos em túneis de vento e coletores de chuva sobre fachadas (COUPER, $1972^{4}$ apud PETRUCCI, 2000).

Tabela 5 - Média das medições de umidade superficial por localização

\begin{tabular}{|c|c|c|c|}
\hline \multirow[b]{2}{*}{$\begin{array}{l}\text { Orientação } \\
\text { da fachada }\end{array}$} & \multicolumn{2}{|c|}{ Local da medição } & \multirow[b]{2}{*}{ Média (\%) } \\
\hline & $\begin{array}{c}\text { Embaixo da } \\
\text { janela }(\%)\end{array}$ & $\begin{array}{l}\text { Ao lado da } \\
\text { janela }(\%)\end{array}$ & \\
\hline $\mathbf{N}$ & 12,0 & 10,2 & 11,1 \\
\hline $\mathbf{E}$ & 4,6 & 3,8 & 4,2 \\
\hline $\mathbf{S}$ & 4,1 & 3,4 & 3,8 \\
\hline $\mathbf{O}$ & 6,2 & 4,8 & 5,5 \\
\hline
\end{tabular}

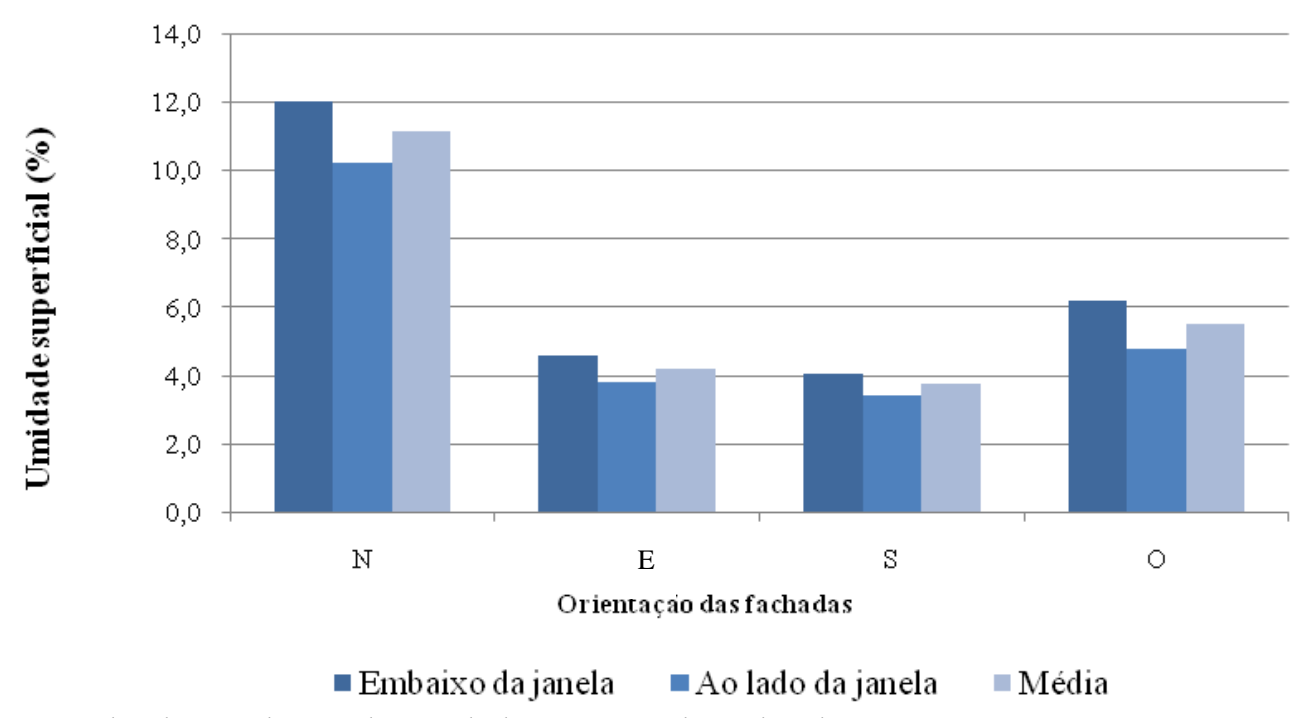

Figura 11 - Média das medições de umidade superficial por localização

\footnotetext{
${ }^{5}$ COUPER, R. R. Drainage From Vertical Surfaces. In: DIVISION OF BUILDING RESEARCH. Wind Driven-Rain and the Multi-Storey Building. Australia: Division of Building Research, CSIRO, 1972.
} 
Tabela 6 - Média das medições de umidade superficial por pavimento

\begin{tabular}{cccc}
\hline $\begin{array}{c}\text { Orientação da } \\
\text { fachada }\end{array}$ & \multicolumn{3}{c}{ Pavimentos } \\
\cline { 2 - 4 } & $\mathbf{2}^{\circ}$ andar (\%) & $\mathbf{9}^{\circ}$ andar (\%) & $\mathbf{1 7}^{\circ}$ andar (\%) \\
\hline $\mathbf{N}$ & 12,1 & 10,7 & 10,7 \\
$\mathbf{E}$ & 4,6 & 3,7 & 4,3 \\
$\mathbf{S}$ & 4,2 & 3,4 & 3,6 \\
$\mathbf{O}$ & 4,1 & 4,3 & 8,1 \\
\hline Média (\%) & 6,2 & 5,5 & 6,7 \\
\hline
\end{tabular}

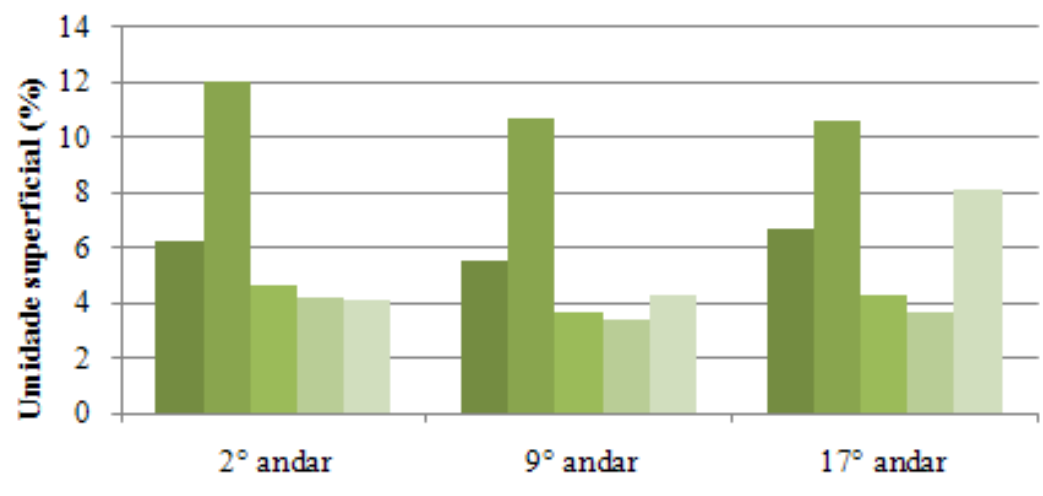

Andares

Média $\quad \mathrm{N} \quad \square \mathrm{E} \quad \square \mathrm{S} \quad \square \mathrm{O}$

Figura 12 - Média das medições de umidade superficial por pavimento

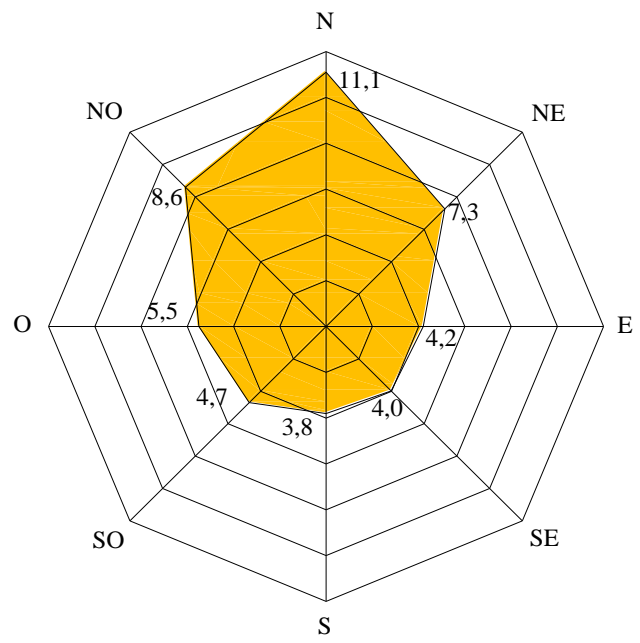

MEDIÇÃO DE UMIDADE (\%)

Figura 13 - Média global da umidade superficial nas fachadas

Os valores médios globais de umidade superficial nas fachadas também foram transformados em gráfico do tipo radar, o mesmo tipo empregado para a representação gráfica dos índices de chuva dirigida direcionais, por meio das médias das medições próximas aos vértices da edificação (Figura 13).
Visando confrontar os resultados dos índices de chuva dirigida direcionais (calculados para Goiânia no mês de janeiro) com os valores de umidade superficial medidos experimentalmente nas fachadas do edifício, foi traçado o gráfico da Figura 14, onde é apresentada a interseção dos dois radares obtidos anteriormente, do ICDd (Figura 9) e da umidade superficial (Figura 13). 


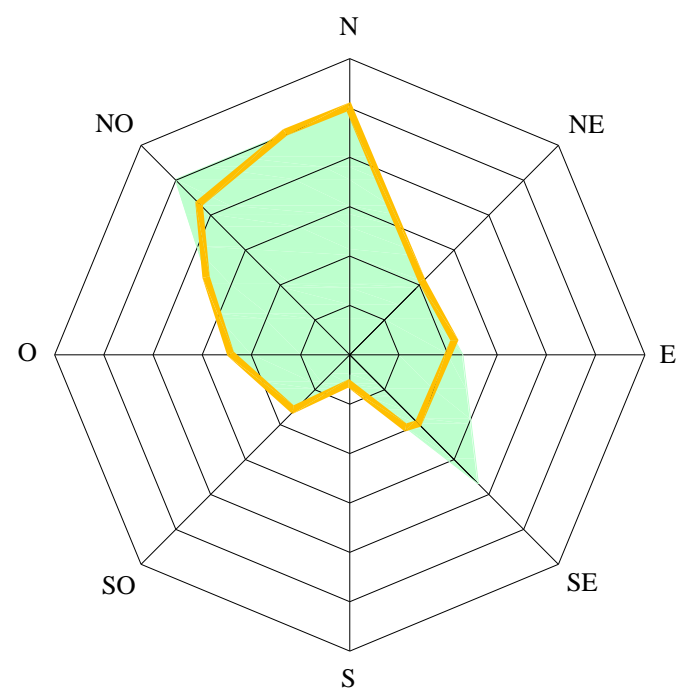

Figura 14 - Interseção dos resultados obtidos pelo ICDd de janeiro e pela medição de umidade

No gráfico de interseção, mostrado anteriormente, pode-se perceber grande similaridade entre os traçados do ICDd de janeiro e da umidade superficial, mostrando uma relação muito boa dos resultados obtidos por cálculo pelo método semiempírico com as medidas realizadas experimentalmente nas fachadas de um edifício, em uma época do ano específica. Isso significa que o cálculo da chuva dirigida pelo método semiempírico pode ser muito útil para os estudos de degradação de fachadas, uma vez que apresenta boa correlação com a real umidade existente na superfície dos revestimentos.

O índice anual de chuva dirigida também foi calculado com o objetivo de buscar mais informações. No período de 2002 a 2008, a média foi de 2,01 m²/s e, de acordo com a Tabela 2, proposta por Chand e Bhargava (2002), Goiânia situa-se numa região protegida, diferentemente do que foi avaliado na pesquisa de Lima e Morelli (2005). Apesar de aquele índice ter sido baixo, se comparado com valores indicados pela literatura (em que é considerado um grau de exposição alto a partir de $7 \mathrm{~m}^{2} / \mathrm{s}$ ), observou-se que em algumas regiões das fachadas analisadas a argamassa de revestimento estava praticamente saturada. Isso pode demonstrar que as escalas internacionais de agressividade não estão adequadas para edifícios altos, onde, devida à altura, pode molhar muito mais no topo dos edifícios; cabe salientar que os aparelhos de medida das estações meteorológicas estão instalados em alturas relativamente baixas (10 m).

\section{Conclusões}

Da pesquisa realizada, pode-se tirar as conclusões a seguir.

A média do ICDd de todos os meses e o ICDd de janeiro, ambos referentes ao período de 2002 a 2008, indicam níveis bastante diferentes de chuva dirigida ao longo do ano.

As medições de umidade superficial nas fachadas do edifício apontaram no período específico a ocorrência de maior umedecimento para as fachadas voltadas à orientação $\mathrm{N}$. O pavimentotipo do $17^{\circ}$ andar apresentou maiores valores de umedecimento, assim como as regiões abaixo das aberturas de janelas, em relação às regiões laterais às aberturas. Esse último aspecto pode ser explicado pelas ausências de esquadria de vedação da janela e de peitoril.

Fazendo a interseção dos radares do ICDd específico do mês avaliado (janeiro) e da umidade superficial medida nas fachadas, obteve-se a confirmação do método, estando o quadrante $\mathrm{N}$ mais exposto à chuva dirigida, e o quadrante $\mathrm{S}$, menos exposto à umidade da chuva.

Concluindo, estudos dessa natureza são fundamentais para identificar as fachadas mais expostas à chuva dirigida, pois o comportamento varia de localidade para localidade. Isso pode ser comprovado se comparados os resultados da presente pesquisa com o estudo de Giongo (2007), em que a maior incidência de chuva dirigida ocorreu no quadrante $\mathrm{S}$.

Pode-se, ainda, traçar algumas considerações finais sobre o tema em questão. 
A quantidade de trabalhos no Brasil que abordam o tema chuva dirigida ainda é bastante pequena. Isso talvez seja justificado, em parte, pela grande dificuldade que os pesquisadores têm de obter dados climáticos junto aos órgãos que fazem medições meteorológicas. O estudo da chuva dirigida se faz importante para a análise da agressividade do meio no qual a edificação se encontra, proporcionando informações que levem à maior durabilidade das fachadas. Com base nesses conhecimentos, é possível a proposição de soluções em projeto com o intuito de prevenção de problemas, uma vez que a reparação das fachadas é dispendiosa e de difícil execução.

Com base nos resultados obtidos de ICDd e umidade, para a cidade de Goiânia, pode-se considerar alguns aspectos para a prevenção de manifestações patológicas associadas à umidade, tais como a infiltração, a formação de sujidade e o crescimento de microrganismos, aspectos esses estudados por Melo Jr. (2010), que são:

(a) as fachadas voltadas principalmente para as direções N e NO estão mais expostas à incidência de chuva dirigida, devendo ter-se maior cuidado com fissuras, que podem tornar-se caminho para a penetração de umidade;

(b) os pavimentos superiores também estão mais expostos à umidade, que, em excesso, pode propiciar o aparecimento de manchas provocadas pelo crescimento de determinados microrganismos nos elementos que compõem as fachadas (vedações, platibandas e demais elementos com característica de horizontalidade); e

(c) as regiões próximo aos peitoris de janelas apresentam maiores índices de umedecimento, que podem levar ao surgimento de manchamento do tipo "bigode".

\section{Referências}

BLOCKEN, B.; CARMELIET, J. A Review of Wind-Driven Rain Research in Building Science. Journal of Wind Engineering and Industrial Aerodynamics, v. 92, n. 13, p. 1079-1130, nov. 2004.

CHAND, I.; BHARGAVA, P. K. Estimation of Driving Rain Index for India. Building and Environment, v. 37, n. 5, p. 549-554, maio 2002.

CHOI, E. C. C. Wind-Driven Rain on Building Faces and the Driving-Rain Index. Journal of Wind Engineering and Industrial Aerodynamics, v. 79, n. 1/2, p.105-122, jan. 1999.
FERNANDES, A. M. C. P. Clima, Homem e Arquitetura. Goiânia: Trilhas Urbanas, 2006.

GASPAR, P.; BRITO, J. de. Mapping Defect Sensitivity in External Mortar Renders.

Construction and Building Materials, v. 19, n. 8, p. 571-578, out. 2005.

GIONGO, M. Análise do Nível de Exposição das Edificações à Chuva Dirigida para

Florianópolis. 107 f. Florianópolis, 2007.

Dissertação (Mestrado em Engenharia Civil) Escola de Engenharia, Universidade Federal de Santa Catarina, Florianópolis, 2007.

LIMA, M. G.; MORELLI, F. Mapa Brasileiro de "Chuva Dirigida": algumas considerações. In: SIMPÓSIO BRASILEIRO DE TECNOLOGIA DE ARGAMASSA, 6.; FLORIANÓPOLIS E INTERNATIONAL SYMPOSIOUM ON MORTARS TECHNOLOGY, 1., 2005 , Florianópolis. Anais... Florianópolis, 2005.

MARSH, P. Air and Rain Penetration of Buildings. London: The Construction Press, 1977.

MELO JUNIOR, C. M. Influência da Chuva Dirigida e dos Detalhes Arquitetônicos na Durabilidade de Revestimentos de Fachada. 204 f. Goiânia, 2010. Dissertação (Mestrado em Geotecnia) - Programa de Pós-Graduação em Geotecnia, Construção Civil e Mecânica das Estruturas, Universidade Federal de Goiás, Goiânia, 2010.

PEREZ, A. R. Umidade nas Edificações: recomendações para a prevenção da penetração de água pelas fachadas, $1^{\mathrm{a}}$ parte. São Paulo: Pini, 1988. p. 571-574. Tecnologia de edificações.

PETRUCCI, H. M. C. A Alteração da Aparência das Fachadas dos Edifícios: interação entre as condições ambientais e a forma construída. 2000. Dissertação (Mestrado em Engenharia Civil) Escola de Engenharia, Universidade Federal do Rio Grande do Sul, Porto Alegre, 2000.

SOUZA, R. H. F. de; ALMEIDA, I. R.; VERÇOSA D. K. Fachadas Prediais: considerações sobre o projeto, os materiais, a execução, a utilização, a manutenção e a deterioração. Revista Internacional Construlink, v. 3, n. 8, p. 1-8, 2005.

STRAUBE, J. F.; BURNETT, E. F. P. Simplified Prediction of Driving Rain on Buildings. In: INTERNATIONAL BUILDING PHYSICS CONFERENCE, Eindhoven, Netherlands. 2000. Proceedings... Eindhoven, Netherlands, 2000. p. 375-382.

THOMAZ, E. Manual Técnico de Alvenaria: patologia. São Paulo: Projeto, 1990. p. 97-117. 


\section{Agradecimentos}

O presente trabalho foi realizado com o apoio da Coordenação de Aperfeiçoamento de Pessoal de Nível Superior (Capes) e Pró-Engenharias.

Revista Ambiente Construído Associação Nacional de Tecnologia do Ambiente Construído Av. Osvaldo Aranha, $99-3^{\circ}$ andar, Centro Porto Alegre - RS - Brasil CEP $90035-190$

Telefone: +55 (51) 3308-4084

Fax: +55 (51) 3308-4054

www.seer.ufrgs.br/ambienteconstruido E-mail: ambienteconstruido@ufrgs.br 